\title{
Microstructural characterization of thermo-mechanical treated TRIP steels
}

\author{
A. Barcellona ${ }^{1, a}$, L. Cannizzaro ${ }^{1, b}$ and D. Palmeri ${ }^{1, c}$ \\ ${ }^{1}$ University of Palermo, Department of Manufacturing Processes and Management Engineering - \\ Viale delle Scienze 90128, Palermo, Italy, \\ abarce@dtpm.unipa.it, ${ }^{\mathrm{l}}$ Icannizz@dtpm.unipa.it, ${ }^{\mathrm{c}}$ palmeri@dtpm.unipa.it
}

Keywords: TRIP effect, Bake Hardening, Work Hardening, Retained Austenite, Multi-Phase steels.

\begin{abstract}
The increasing demand for the reduction of automobiles $\mathrm{CO}_{2}$ emissions for environmental preservation leads the automotive industries towards the mechanical components weight reduction. Sheet steels with multiphase microstructures exhibit favourable combinations of strength and ductility. The so called TRIP steels have a metastable microstructure that consists of a continuous ferrite matrix containing a dispersion of hard second phases martensite and bainite. These steels also contain retained austenite, at room temperature, that represents the source of the TRansformation Induced Plasticity effect. When the material is subjected to deformation step, the retained austenite transforms itself into martensite; the produced martensite delays the onset of necking resulting in a product with high total elongation, excellent formability and high crash energy absorption. In the present research the steel TRIP 800 zinc coated has been subjected to different thermo-mechanical treatments in order to evaluate the relation between microstructure of material and TRIP effects. Whit this aim the microstructural analysis has been performed and the evaluation of content of different phases has been made by means of the image analysis techniques. The relation among the strain level, the content of different phases, the thermal treatments and the work hardening properties of materials have been valued. Furthermore, it has been also highlighted the dependence of the bake hardening properties of material on the different thermo-mechanical treatments.
\end{abstract}

\section{Introduction}

In the last two decades the increasing request of energy saving pushed the steel users toward the search of materials with high strength values and excellent formability. In fact the weight reduction became one of the most important goal in the automotive industry. To ensure that steel remains the material of choice for automotive bodies, it is necessary to make ultra lightweight automobiles using advanced steels. Furthermore, it is necessary to observe that the safety and comfort requests of the automotive market can be in contradiction with the pursuit of lighter weight. In order to solve these contradictions, it is necessary to use, for the structural parts of cars, materials with large value of strength-ductility balance and therefore also large toughness values. This condition may be guarantied by the TRansformation Induced Plasticity (TRIP) steels.

These steels have, at room temperature, a multiphase microstructure consisting of a ductile ferrite matrix, hard bainite, hard martensite, and retained austenite in metastable conditions. This particular microstructure can be achieved by means of two different thermal treatments starting from a dual phase steel. In order to obtain a large amount of retained austenite at room temperature, which results fundamental to the trip effect, the material is subjected to an Intercritical Annealing (IA) and an Isothermal Bainite Treatment (IBT). The excellent mechanical and formability properties of TRIP steels result from the martensitic transformation of the retained austenite during mechanical loading; this is the so called TRIP effect. In fact, in order to accommodate the deformation produced by the phase transformation, the regions surrounding the transformed phase undergo a plastic deformation that is added to the deformation produced from the mechanical load. In order to 
understand the relationship between microstructure and mechanical properties, it is necessary to analyze the role of the different phases.

With the aim to evidence and explain the microstructural and the mechanical changes that occur during the production process of the automotive parts, in this research the microstructural modifications that appear as consequence of different work hardening values and also during the thermal treatment connected to the paint baking process, have been studied. In fact during the baking treatments, a microstructural change of material occurs and this occurrence produces an increasing in the yield strength value of the material. From this point of view, the evaluating of the amount of each phase after the different thermo-mechanical treatments and also the variation of mechanical properties in terms of micro-hardness and tensile values represents an important task. The tested material was a TRIP $800 \mathrm{C}-\mathrm{Mn}$-Si zinc coated.

The volume fraction of various phases was valued by means of the coupling of metallographic examinations and image analysis techniques. A double etching procedure was performed in order to highlight with a high contrast level and also with different colours the four different phases. The image analysis, in order to evaluate the percentage of each phase, has been performed using the MATLAB $^{\mathscr{C}}$ image processing toolbox. The different work hardening levels were conferred by means of pre-strain conditions in the tensile tests and also by means of bending tests. The bake treatment has been performed keeping the material at the temperature equal to $170^{\circ} \mathrm{C}$ for 30 minutes and after quenching it in cold water.

\section{TRIP effect, Work Hardening and Bake Hardening}

The understanding of phenomena that rule the microstructural changing of trip steels submitted to different thermo-mechanical treatments, requests the highlighting of influence factors that determine the trip effect. The trip steels are characterized by a very low content of alloying elements, such as in the tested material the total content of alloying elements is about $3.3 \mathrm{wt} . \%$, in particular there are C (0.2 wt.\%), Mn (1.5 wt.\%), Si (0.8 wt.\%), and residual elements $(0.8$ wt.\%). For a given chemical composition the presence of trip effect is produced from two-stage heat treatment after cold rolling. These treatments are called Intercritical Annealing and Isothermal Bainite Treatment [1], [2], [3], [4].

Considering that the carbon is one of the stronger austenite stabiliser element, the amount of the austenite phase at room temperature in metastable condition, is connected to the austenitic carbon content reached during the Isothermal Bainite Treatment. In fact the IBT is the most critical stage of the production process for any trip steel. During this phase three crucial parameters are defined: the $\mathrm{C}$ content, the volume fraction and the size of the retained austenite areas in the microstructure. During the IBT, the carbon, that cannot produce the carbides typical of the bainitic phase because of the silicon presence, diffuses into the austenitic regions and leads to the stability of the retained austenite at room temperature. The final amount of retained austenite depends on the holding time during the IBT step without carbide precipitation phenomena and also on the Si content. The silicon alloying determines also the ferrite matrix strengthening by means of solid solution.

The trip effect arises from the strain-induced transformation of retained austenite to martensite; this transformation results accompanied by a volume expansion that generates plastic deformation and the work hardening of surrounding ferritic phases. In fact during the first phase of the deformation process, the hard phases dispersed in soft ferrite, i.e. bainite and thermal activated martensite, produce an increasing of the density of dislocations and therefore an high initial value of work hardening rate. This phenomenon determines a high initial slope in the flow stress curve of material. Furthermore, in trip steel, during the whole deformation process, the retained austenite progressively transforms to the martensite at increasing of the strain level. This phenomenon determines high work hardening rate and therefore flow stress curve slope, also for higher strain values. The persistence of high work hardening rate may be attributed to the formation of stress induced martensite and the accumulation of dislocations in the soft ferritic matrix. Therefore this 
strain-induced transformation determines high uniform elongation and also high stress level; furthermore it delays the onset of necking and increases the crash energy absorption capability of material. Finally, the martensitic transformation generates inside the material a compression stress that confers to it high fatigue resistance.

The bake hardening phenomenon consists in the increasing of yield properties of material after the paint baking treatment. This treatment consists in the aging of material at $170^{\circ} \mathrm{C}$ for 30 minutes. Many factors, such as bainite phase-transformation, starting of the retained austenite, increase of carbon content in the retained austenite, decrease of the retained austenite content, increase of martensite, and increase of the dislocation density in ferrite matrix, influence the yielding phenomenon of tensile-strained and baked trip steel sheets [5], [6], [7].

It is possible to distinguish different contributes inside the yield variation connected to the baking treatment. There is an increment of yield stress produced into the ferritic matrix due to an activate diffusion of the solid solute that determines an hindrance of dislocation movement. Another contribute of yield increment is produced from the increasing of the carbon content in the retained austenite during baking, the produced solid solute strengthening effect determines the strength of retained austenite. It need also to remarks that during the baking treatment there is a decrease on the amount of the retained austenite due to the austenite transformation to bainite, that is more stable at the given temperature. Each contribution on the yield properties of material is connected on the amount of each phase. During bake hardening treatment, the amount an therefore the yield contribution of the martensitic phase, does not change [8], [9], [10], [11].

\section{Experimental Procedures}

Experiments were performed on $1 \mathrm{~mm}$ thin sheets of TRIP 800 zinc coated with $\mathrm{C}(0.2 \mathrm{wt} . \%)$, Mn (1.5 wt.\%), Si (0.8 wt.\%). Two different kind of specimens have been made: the smaller one for the bending tests $(10 \times 60 \mathrm{~mm})$ and the larger $(10 \times 80 \mathrm{~mm})$ for the tensile tests. After the thermomechanical treatments, the effect of the employed parameters has been valued both in term of change of percentage of each phase and also tensile and ductility properties.

Mechanical Treatments. In order to highlight the different influence of WH effect on microstructure and mechanical properties of material, two mechanical tests and also micro hardness Vickers tests have been performed. Bending tests on strip specimens of 10x60 mm dimensions allowed to determine the effect of WH on the microstructure of material. In fact a high level of WH is reached in the bending region, and therefore the metallographic examination of this region allows to evaluate the trend of the amount of present phases when the WH phenomenon happens.

In Fig. 1 A the used experimental set up for the bending tests is shown. The punch dimension was chosen equal to $0.5 \mathrm{~mm}$ of radius in order to obtain an high WH value in the bent region. The tensile tests were performed on the base material and on the thermal treated material using strip specimens of $10 \times 80 \mathrm{~mm}$ dimensions. Furthermore pre-strained specimens, with the same dimension, were made with two different pre-strain values equal to $5.0 \%$ and $7.5 \%$ and also these specimens were subjected to tensile tests before and after the thermal treatment.

Thermal Treatments. In order to evaluate the effect of the paint baking treatment on microstructure and mechanical behaviour of material, both the bent and pre-strained with different pre-strain values specimens, have been subjected to the same thermal treatment that simulate the typical thermal cycle of paint baking process. Therefore the material was brought to a temperature equal to $170^{\circ} \mathrm{C}$ for 30 minutes and after it was quenched in water. In order to evaluate only the $\mathrm{BH}$ effect on the material, the thermal treatment was performed on the specimens without any bending or pre-strain. The influence of $\mathrm{BH}$ treatment on the microstructure of material was highlighted through the evaluation of difference in the amount of each phase. 


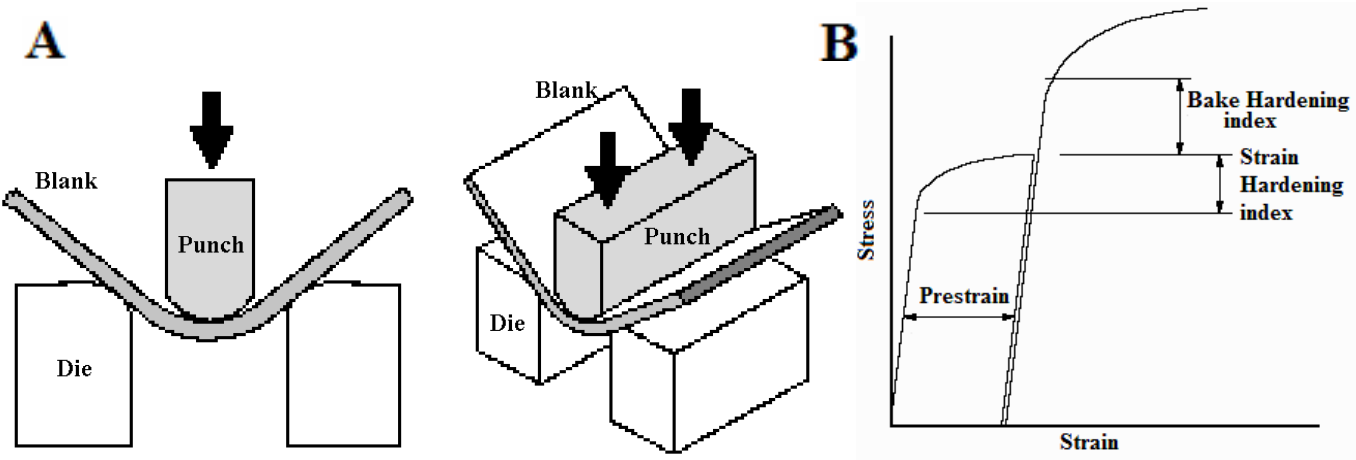

Fig. 1: A) Experimental set up for the bending tests, B) Bake Hardening index.

Instead the effect of $\mathrm{BH}$ treatment on the mechanical properties of material has been made by means of the computation of BH index (Fig.1 B), defined as:

$$
\mathrm{BH}=\mathrm{YS}_{\mathrm{pBH}}-\sigma_{\mathrm{Bp}}
$$

In the Eq. $1 \mathrm{YS}_{\mathrm{pBH}}$ is the reached yield stress on the material pre-strained and bake hardened, whereas $\sigma_{\mathrm{Bp}}$ represent the yield stress value that should be found in the pre-strained material without $\mathrm{BH}$ treatment. Also the coupled effect of $\mathrm{BH}$ and $\mathrm{WH}$ on the material properties has been valued. In fact the evaluation of the Strength Ductility Balance index, defined as the following product:

$$
\mathrm{SDB}=\mathrm{UTS} \times \varepsilon_{\mathrm{UTS}}
$$

in which $\varepsilon_{U T S}$ is the reached strain corresponding to the UTS stress value, allowed to obtain the effect of both the treatments, mechanical and thermal, on the formability properties of material. Another evaluated index, that takes in to account the formability properties, is the difference among the UTS and YS value for each thermo-mechanical treated specimens.

Microstructural Analysis. The fundamental influence of microstructure on physical and mechanical properties of material, makes the metallographic examination a necessity for a proper understanding and improvement of the mechanical behavior. The possibility to distinguish, whit an high contrast level, the different phases after the etching procedure, constitutes the main problem in the metallographic examination of multiphase materials. In fact the etching process produces a selective dissolution or preferential colour of the present phases. In the case of multiphase material each etching technique allows to highlight only some phases among that one are present.

In order to solve this problem a double etching technique has been set up. Firstly the microstructures were highlighted by chemical etching with Le Pera tint reagent, for times ranging from 5 to $15 \mathrm{~s}$ depending on the thermo-mechanical treatment, on the surfaces that had been mechanically ground and then polished with diamond paste $(1 \mu \mathrm{m})$. This first phase allowed to distinguish only the ferritic matrix and the bainitic phase from the austenitic and martensitic phases. After this step each specimen was subjected to a second etching process using the Nital $2 \%$ reagent for a time equal to 5 seconds for all the thermo-mechanical treated materials. The first etching modified the selective properties of the martensitic areas, in fact after the second etching, these appear with a different colour from the other phases. After Le Pera etching, the martensitic and austenitic phases appear white, the bainitic one is gray, ferrite is light brown. The second step etching allows to distinguish the martensite phase from the austenite one, with different colours. The martensitic phase appears blue-violet, the bainitic one is blue green, ferrite is light brown and austenite is white. The contrast level among the martensitic and bainitic phase result higher after $\mathrm{BH}$ treatment because of the carbide precipitation phenomenon that occurs in the martensitic phase. 

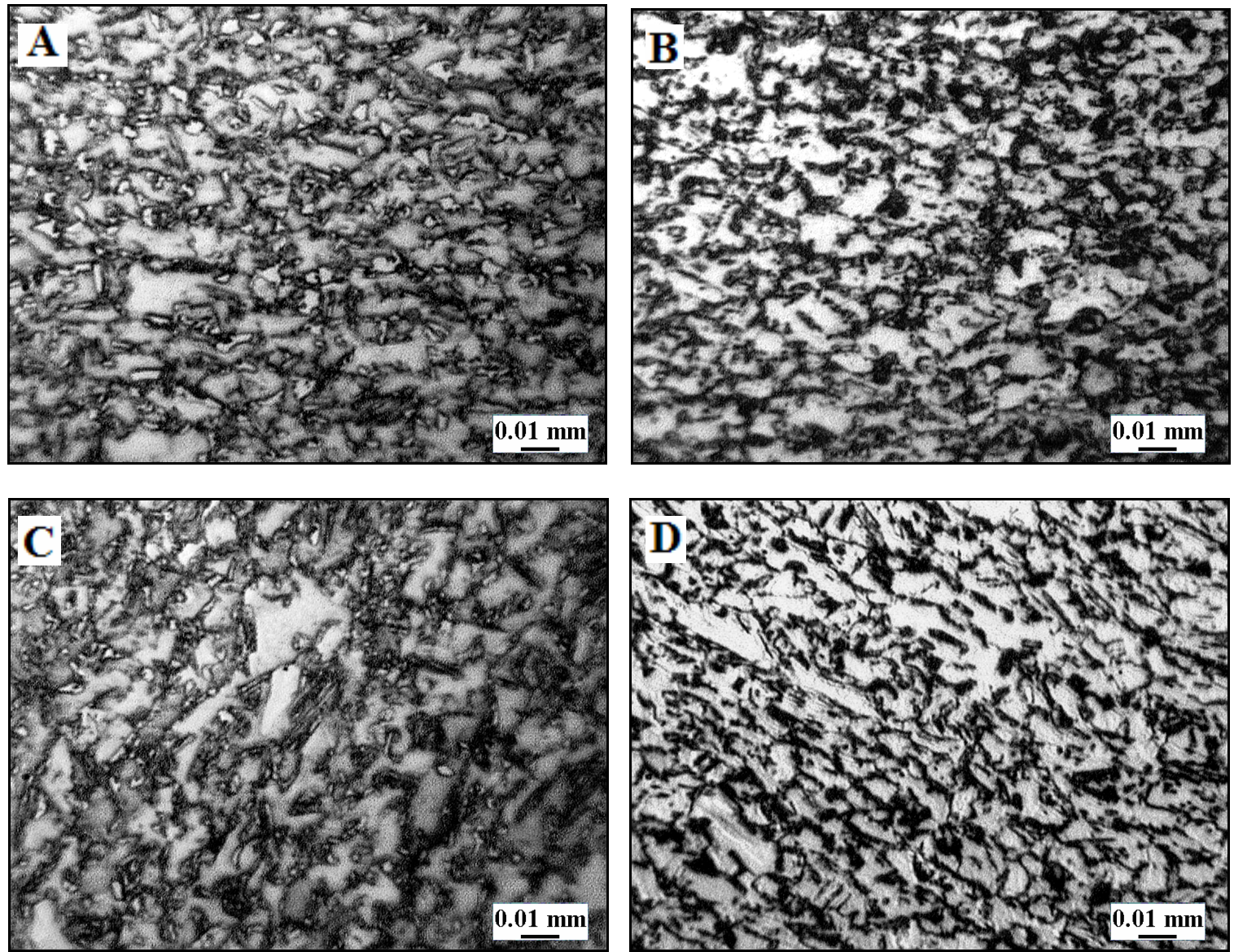

Fig. 2: A) Trip base, B) Trip base BH, C) Trip base WH, D) Trip base WH and BH.

In Fig. 2 it is possible to observe the obtained microstructure at varying of the thermo-mechanical treatment of material. The microstructural analysis allowed also to obtain the mean grain dimension for each phase.

Image Analysis. The image analysis technique allowed to evaluate the amount of each phase depending on the thermo-mechanical history of material. The used tool was the MATLAB ${ }^{\odot}$ image processing toolbox. Starting from each micrography, as shown in Fig. 3, depending on the phase that has to be highlighted, firstly an image whit better contrast of the considered phase using a proper level contrast value was obtained. At this step, the RGB enhanced image was converted to a grayscale intensity image. Fixing a proper threshold level, in order to highlight only one phase, a type conversions function allows to convert the input grayscale image to binary by thresholding. Morphological operations allowed to separate the different areas for the phases with similar contrast level. Finally the use of arithmetic function produced a black and white image in which is highlighted only one phase. The display of properties of the image histogram let the computation of amount of the considered phase.

\section{Experimental results and discussion}

In the evaluation of influence of $\mathrm{BH}$ and $\mathrm{WH}$ treatments on the properties of Trip 800 zinc coated steel, two different kinds of results were found. From the metallographic point of view, the only BH treatment involves a considerable reduction in the amount of retained austenite, from the $6.2 \%$ to the $2.0 \%$ value. Starting from the austenitic phase begins the production of an added amount of bainitic phase that achieves the value of $22 \%$. Therefore only a very small trip effect is still present. As a consequence of the only $\mathrm{WH}$ treatment, it is possible to observe a lower variation in the amount of retained austenite, from $6.2 \%$ to $3.8 \%$ value. 

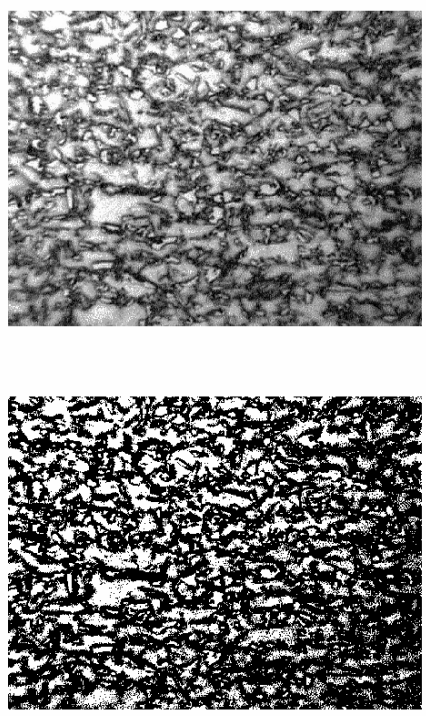
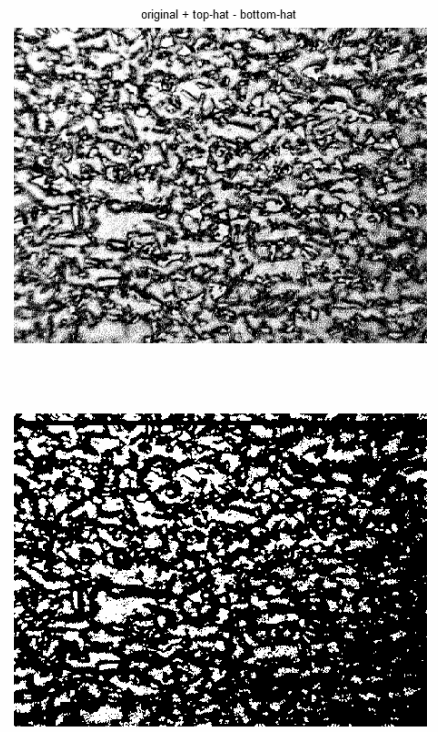
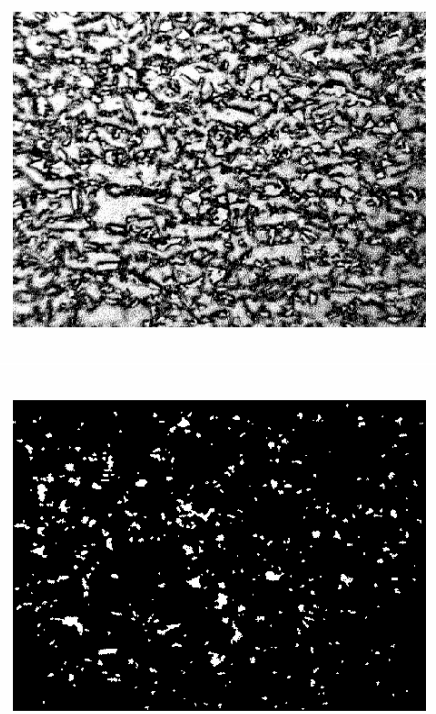

Fig. 3: Different steps of the Image Analysis Process.

A variation in the amount of martensite phase, from $2.8 \%$ to $6.0 \%$, was also found. A preferential orientation of the martensite variants in the loading direction has been observed and also it as been observed a deformation of the initial polygonal ferrite matrix in the same direction. The combined effect of $\mathrm{WH}$ and $\mathrm{BH}$ treatments produces a microstructure with elongated ferritic grains and martensite phase with preferential orientation. Also in this case, the $\mathrm{BH}$ treatment produces a drastic reduction in the amount of the retained austenite, from $6.2 \%$ to $1.8 \%$ value. The carbide precipitation phenomenon, that happens inside the martensite variants, allows to distinguish more clearly the martensitic phase from the bainitic ones. The image analysis results provided an amount of martensite phase equal to $6.1 \%$ and of bainitic phase equal to $17.2 \%$.

The micro-hardness results (Fig. 4 A) show an increasing of the hardness value both for the only $\mathrm{BH}$ and $\mathrm{WH}$ treatments, and also in the coupled case. This phenomenon is connected with the strain hardening and precipitation hardening phenomena that happen in the different phases during the $\mathrm{BH}$ and $\mathrm{WH}$ treatments. The coupled action determines an hardness increment much higher of the single effects addition because the carbide precipitation during the $\mathrm{BH}$ treatment of $\mathrm{WH}$ treated material amplifies the single effects.

From the point of view of mechanical behaviors and therefore of the tensile test results, the consistent reduction on the amount of retained austenite and the production of the bainitic phase, in the only $\mathrm{BH}$ treatment, generate a small $\mathrm{BH}$ effect equal to $18 \mathrm{MPa}$, due to an activate diffusion of the solid solute that determines a strength of ferritic matrix.
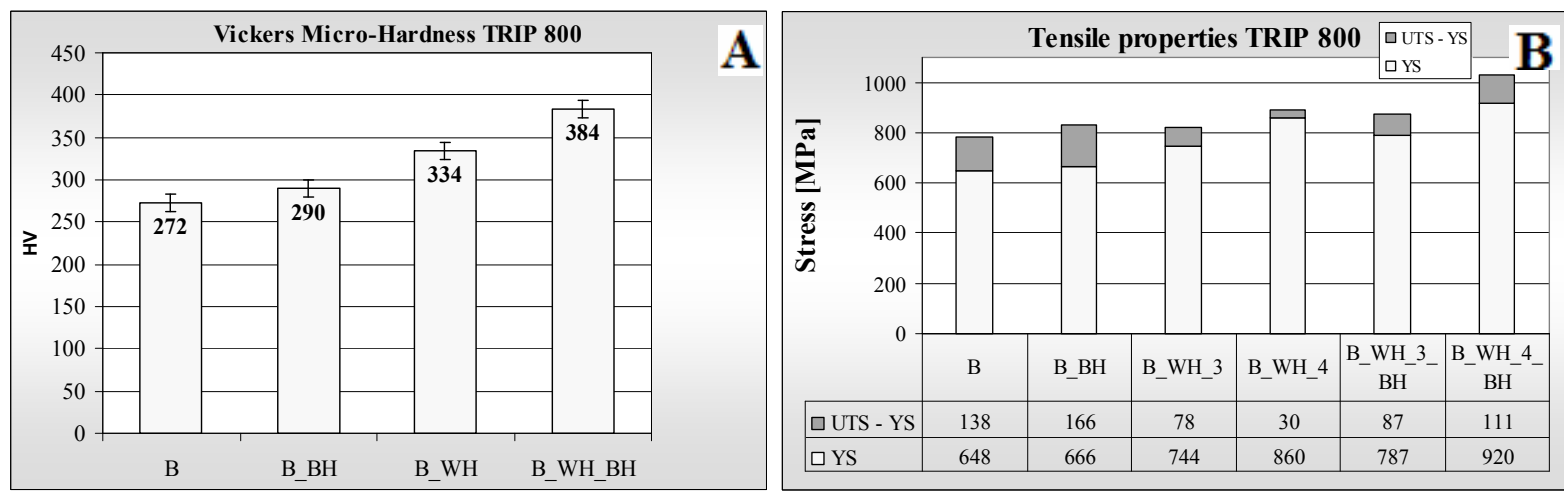

Fig. 4: Mechanical properties: A) micro-hardness value, B) UTS and YS. 


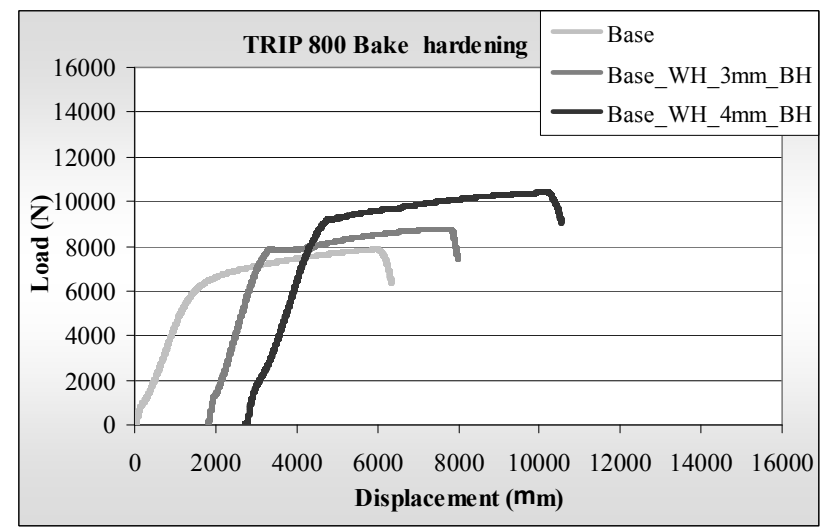

Fig. 5: Bake Hardening effect.

The small amount of austenite and martensite phases determines only a small flattening of the flow stress curve and hence the strain hardening index stays of high value. Instead, the only WH effect determines a strong reduction of strain hardening index due to the high value of martensite fraction, as it is shown in Fig. 4 B. In this case, enhanced mechanical properties were found, but coupled with poor ductility properties, as shown in Fig. 6 A and B.

The $\mathrm{WH}$ followed by $\mathrm{BH}$ coupled treatment determines high values of $\mathrm{BH}$ index depending on the martensitic phase amount. In the specimens $5 \%$ pre strained, a value of $\mathrm{BH}$ index equal to 44 $\mathrm{MPa}$ was found and an higher value equal to $148 \mathrm{MPa}$ has been computed for the $7.5 \%$ pre-strained specimens (Fig. 5). Together to these high mechanical characteristics, also enhanced ductility properties was determined. Therefore the only high level of martensite fraction coupled with a reduction of retained austenite amount, determines the loss of ductility properties, as it is possible to see in Fig. 6. Both a recovery in term of ductility and of mechanical properties was produced from the subsequent $\mathrm{BH}$ treatment. The many activate hardening processes in the different phases, as strain hardening, precipitation hardening and solid solution hardening allowed to preserve an high work hardening rate during all the deformation process.

\section{Conclusions}

In this work the influence of Work Hardening (WH) and Bake Hardening (BH) treatments on the properties of TRIP 800 zinc coated steel sheets was studied. The change in terms of microstructure and mechanical behaviour has been analyzed. The following main results have been found:

- The employed double etching technique allowed to distinguish with an high contrast level the four different phases typical in the microstructure of the trip steels. In fact the difficult to distinguish the martensite phase from the austenite one was overcame by means of a modification on the etching sensibility of two phases using a second step etching with $2 \%$ natal.
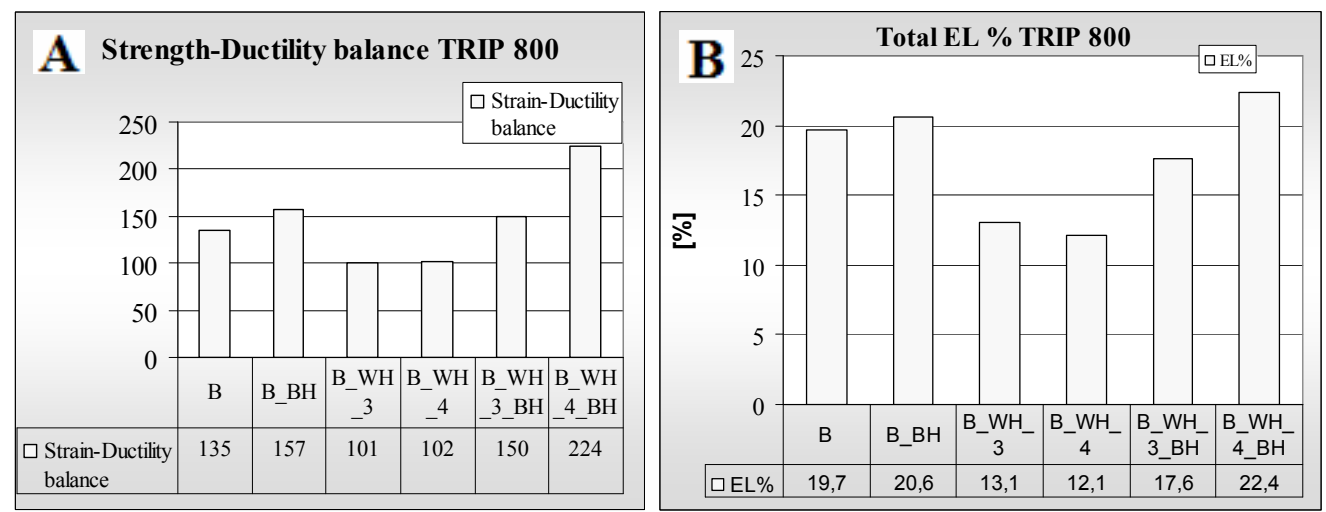

Fig. 6: A) and B) crash energy absorption properties and formability. 
After the second etching step, the martensitic phase appears blue-violet, the bainitic one is blue green, ferrite is light brown and austenite is white.

- By means of the image analysis technique, the amount of the different phases before and after thermo-mechanical treatment was valued.

- The only WH treatment (pre-strain) determine an increasing of UTS and YS values of material to detriment of the ductility of material and also a decreasing on the amount of retained austenite. In this case, because of the pre-strain, only a small trip effect happens.

- The only BH treatment determines a large reduction of the amount of retained austenite, and therefore the trip effect result almost insignificant.

- The BH treatment after $\mathrm{WH}$, because of the carbide precipitation in the martensitic phase, produces a considerable increment of strain hardening index and also improved ductility properties were found.

\section{References}

[1] Ashok Kumar Srivastava a, G. Jha, N. Gope, S.B. Singh: Effect of heat treatment on microstructure and mechanical properties of cold rolled $\mathrm{C}-\mathrm{Mn}-\mathrm{Si}$ TRIP-aided steel, Materials Characterization 57, (2006), 127-135.

[2] X.D. Wang, B.X. Huang, Y.H. Rong, L. Wang : Microstructures and stability of retained austenite in TRIP steels, Materials Science and Engineering A, (2006), article in press.

[3] A. Wasilkowska, P. Tsipouridis, E.A. Werner, A. Pichler, S. Traint: Microstructure and tensile behaviour of cold-rolled TRIP-aided steels, Journal of Materials Processing Technology 157-158, (2004), 633-636.

[4] E. Girault, A. Mertens, P. Jacques, Y. Houbaert, B. Verlinden, J. Van Humbeeck: Comparison Of The Effects Of Silicon And Aluminium On The Tensile Behaviour Of Multiphase Trip-Assisted Steels, Scripta mater. 44, (2001), 885-892.

[5] Huo Yan-Qiu, Long Xiu-Hui, Zhou Zhen-Hua, Li Jian-Guo: Bainite transformation and TRIP effect in 20Mn2SiVB steel, Materials Science and Engineering A, (2006), article in press.

[6] Wen Shi, Lin Li, Chun-Xia Yang, Ren-Yu Fu, Li Wang, Partick Wollants: Strain-induced transformation of retained austenite in low-carbon low-silicon TRIP steel containing aluminum and vanadium, Materials Science and Engineering A, 429, (2006), 247-251.

[7] S. Oliver, T.B. Jones, G. Fourlaris: Dual phase versus TRIP strip steels: Microstructural changes as a consequence of quasi-static and dynamic tensile testing, Materials Characterization, (2006), article in press.

[8] J. Bouquerel, K. Verbeken, B.C. De Cooman: Microstructure-based model for the static mechanical behaviour of multiphase steels, Acta Materialia, 54, (2006), 1443-1456.

[9] Z.C. Wang, S.J. Kim, C.G. Lee, T.H. Lee: Bake-hardening behavior of cold-rolled CMnSi and CMnSiCu TRIP-aided steel sheets, Journal of Materials Processing Technology, 151, (2004), 141145.

[10]S. Zaefferer, J. Ohlert, W. Bleck: A study of microstructure, transformation mechanisms and correlation between microstructure and mechanical properties of a low alloyed TRIP steel, Acta Materialia, 52, (2004), 2765-2778.

[11]B.C. De Cooman: Structure-properties relationship in TRIP steels containing carbide-free bainite, Current Opinion in Solid State and Materials Science, 8, (2004), 285-303. 